\title{
Growth in Length during the Transition from Larva to Adolescent in the Pilchard and Sprat.
}

\author{
$\mathrm{By}$ \\ E. Ford, A.R.C.Sc., \\ Fisheries Naturalist at the Plymouth Laboratory.
}

With 1 Figure in the Text.

\section{INTRODUCTION.}

In a previous paper (Ford, 1) it was shown that during the transition from larva to adolescent in the herring, there was a progressive alteration in position of the anus and fins relative to one another and to the vertebrae. Simple models of tape and elastic were utilised to demonstrate how such changes in position could be induced on the assumption that different intervals along the body grew in length at unequal rates. It will be recalled that for the herring it was accepted that two such intervals, namely, (1) from the back of the head, along the dorsal surface, to the first ray of the dorsal fin; and (2) from the insertion of the pelvies, along the ventral surface to the anus, remained at a steady unchanging length throughout the transition stages. Meanwhile, other body-intervals increased in length, each at its own rate.

With the necessary material available for the study, similar investigations have since been made for the sprat and the pilchard, and it is the purpose of the present publication to discuss the results so obtained.

\section{METHODS.}

As in the case of the young herrings, determinations of the length of the following body-intervals were made (see Fig. 1) :-

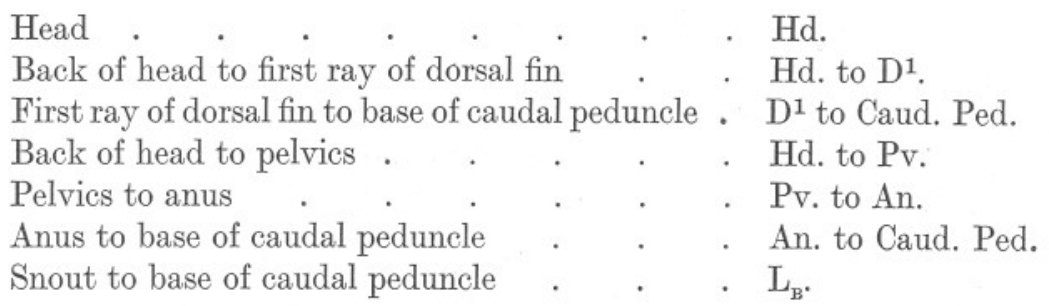


Having completed the measurement, the data were grouped into classes according to the length of $\left(\mathrm{L}_{\mathrm{B}}-\mathrm{Hd}\right.$.), that is to say, according to the length of the distance from the back of the brain to the base of the caudal peduncle.

The Pilchard (Clupea pilchardus Walbaum).

The data for a total of 261 measured specimens were as shown in Table 1. (See p. 979.) Examining the figures relating to the two intervals ( $\mathrm{Hd}$. to $\mathrm{D}^{1}$ ) and $\left(\mathrm{Pv}\right.$. to $\mathrm{An}$.), it is seen that $\left(\mathrm{Hd}\right.$. to $\left.\mathrm{D}^{1}\right)$ varies but little from an average figure of about $10.5 \mathrm{~mm}$., whereas the values of ( $\mathrm{Pv}$. to An.) tend to increase as the value of $\left(\mathrm{L}_{\mathrm{B}}-\mathrm{Hd}\right.$.) increases. The pilchard thus resembles the herring in that the length from the back of the brain to the first dorsal ray appears to remain steady throughout the transition from larva to adolescent, but differs from the herring in that the distance from the pelvics to the anus increases instead of remaining unchanged throughout metamorphosis.

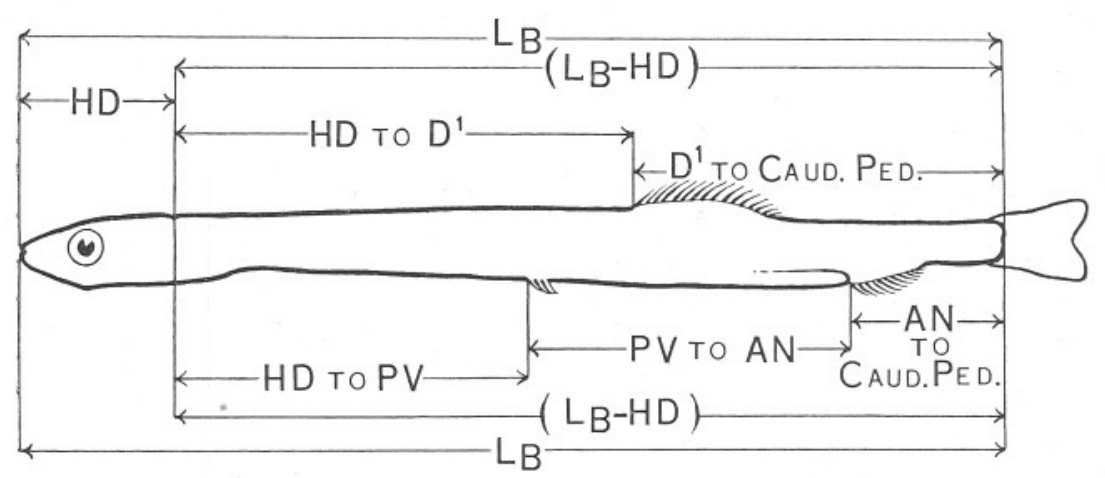

Fra. 1.-Diagrammatic representation of young clupeoid to illustrate meaning of symbols used in the text.

Snout to end of caudal peduncle . . . . . $\mathrm{L}_{\mathrm{B}}$.

Snout to back of head . . . . . . $\quad . \quad \mathrm{Hd}$.

Back of head to end of caudal peduncle . . . ( $\mathrm{L}_{\mathrm{B}}-\mathrm{Hd}$.)

Back of head to first ray of dorsal fin . . . Hd. to $\mathrm{D}^{1}$.

First dorsal ray to end of caudal peduncle . $\quad . \quad \mathrm{D}^{1}$ to Caud. Ped.

Back of head to pelvics . . . . . Hd. to Pv.

Pelvics to anus . . . . . . . Pv. to An.

Anus to end of caudal peduncle . . . . . An. to Caud. Ped.

With regard to the data in general, it has been determined that the length of a given body-interval can be expressed in terms of $\left(\mathrm{L}_{\mathrm{B}}-\mathrm{Hd}\right.$.) in accordance with a simple equation of the form :

$$
\mathrm{Y}=\mathrm{M}(\mathrm{X})+\mathrm{C}
$$




\section{TABLE 1.}

Average Values (ma.) for each of the following Values of $\mathrm{L}_{\mathrm{B}}-\mathrm{Hd}$ :-

Hd. $\begin{array}{llllllllllllllllllll}18 & 19 & 20 & 21 & 22 & 23 & 24 & 25 & 26 & 27 & 28 & 29 & 30 & 31 & 32 & 33 & 34 & 35 & 36\end{array}$

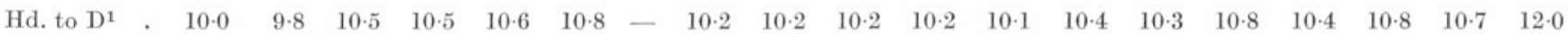

$D^{1}$ to Caud.

$\begin{array}{llllllllllllllllllll}\text { Ped. } & 8 \cdot 0 & 9 \cdot 2 & 9 \cdot 5 & 10 \cdot 5 & 11 \cdot 4 & 12 \cdot 2 & - & 14 \cdot 8 & 15 \cdot 8 & 16 \cdot 8 & 17 \cdot 8 & 18 \cdot 9 & 19 \cdot 6 & 20 \cdot 7 & 21 \cdot 2 & 22 \cdot 6 & 23 \cdot 2 & 24 \cdot 3 & 24 \cdot 0\end{array}$

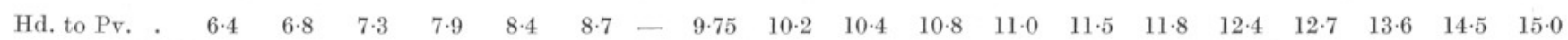

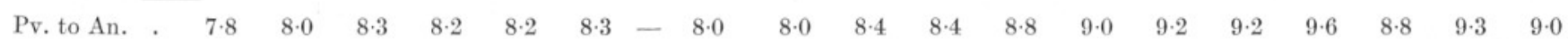
An. to Caud.

$\begin{array}{llllllllllllllllllll}\text { Ped. } & 3 \cdot 6 & 4 \cdot 2 & 4 \cdot 4 & 4 \cdot 9 & 5 \cdot 4 & 6 \cdot 0 & - & 7 \cdot 25 & 7 \cdot 8 & 8 \cdot 2 & 8 \cdot 8 & 9 \cdot 2 & 9 \cdot 5 & 10 \cdot 0 & 10 \cdot 4 & 10 \cdot 7 & 11 \cdot 6 & 11 \cdot 2 & 12 \cdot 0\end{array}$

Total No. of

$\begin{array}{llllllllllllllllllllllll}\text { Spec. } & \cdot & 5 & 9 & 19 & 15 & 5 & 6 & - & 12 & 30 & 39 & 26 & 22 & 21 & 17 & 17 & 9 & 5 & 3 & 1\end{array}$

\section{TABLE 2.}

Values Calculated from Equations-Values of $\left(\mathrm{L}_{\mathrm{B}}-\mathrm{HD}\right)$.

\begin{tabular}{|c|c|c|c|c|c|c|c|c|c|c|c|c|c|c|c|c|c|c|c|}
\hline & 18 & 19 & 20 & 21 & 22 & 23 & 24 & 25 & 26 & 27 & 28 & 29 & 30 & 31 & 32 & 33 & 34 & 35 & 36 \\
\hline d. to $\mathrm{D}^{1}$ & 10.5 & $10 \cdot 5$ & $10 \cdot 5$ & $10 \cdot 5$ & $10 \cdot 5$ & $10 \cdot 5$ & 10.5 & $10 \cdot 5$ & $10 \cdot 5$ & $10 \cdot 5$ & $10 \cdot 5$ & $10 \cdot 5$ & $10 \cdot 5$ & $10 \cdot 5$ & $10 \cdot 5$ & $10 \cdot 5$ & $10 \cdot 5$ & $10 \cdot 5$ & 10 \\
\hline
\end{tabular}
$D^{1}$ to Caud.

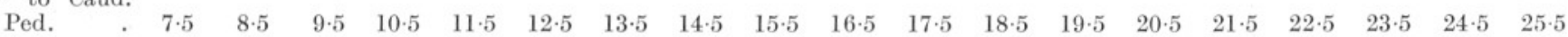
$\begin{array}{llllllllllllllllllll}\text { Hd. to Pv. . } & 6.43 & 6.87 & 7.31 & 7.75 & 8.19 & 8.63 & 9.06 & 9.50 & 9.94 & 10.37 & 10.81 & 11.25 & 11.68 & 12.12 & 12.56 & 13.00 & 13.44 & 13.87 & 14.31\end{array}$

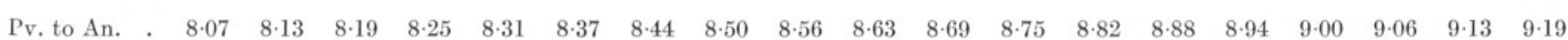
An. to Caud.

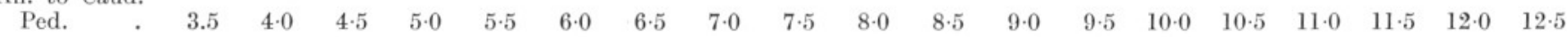


The following equations have been found to give values which approximate reasonably closely to the observed figures :-

(1) $\left(\right.$ Hd. to $\left.\mathrm{D}^{1}\right) \quad=10 \cdot 5$.

(2) $\left(\mathrm{D}^{1}\right.$ to Caud. Ped. $)=\left(\mathrm{L}_{\mathrm{B}}-\mathrm{Hd}\right.$. $)-10 \cdot 5$.

(3) $\left(\mathrm{Hd}\right.$. to $\mathrm{Pv}$.) $=.4375\left(\mathrm{~L}_{\mathrm{B}}-\mathrm{Hd}\right.$. $)-1 \cdot 44$.

(4) (Pv. to An.) =.0625 $\left(\mathrm{L}_{\mathrm{B}}-\mathrm{Hd}\right.$. $)+6 \cdot 94$.

(5) (An. to Caud. Ped. $)=\left(\mathrm{L}_{\mathrm{B}}-\mathrm{Hd}\right.$. $)-(\mathrm{Hd}$. to Pv. $)-(\mathrm{Pv}$. to An.).

How nearly the calculated values approximate to the raw data may be learned by comparing Table 2 with Table 1. (See p. 979.) Accepting equations 1 to 5 above, it is possible to make the following statements :-

For each unit of increase in $\left(\mathrm{L}_{\mathrm{B}}-\mathrm{Hd}\right.$.).

(1) Hd. to $\mathrm{D}^{1} \quad$ increases by $0 \cdot 0000$ unit.

(2) $\mathrm{D}^{1}$ to Caud. Ped. , , , 1.0000 ,,

(3) Hd. to Pv. , , , 0.4375 ,

(4) Pv. to An. , , , , 0.0625 ,

(5) An. to Caud. Ped. ,, , 0.5000 ,,

\section{The Sprat (Clupea sprattus L.).}

The corresponding data for a total of 136 sprats were :-

\section{TABLE 3.}

Average Values (mm.) for each of the following Values of ( $\mathrm{L}_{\mathrm{B}}-\mathrm{Hd}$.).

Hd.

Hd. $\mathrm{H}$. $\quad . \quad 3 \cdot 75$

$\begin{array}{lllllllllll}\mathrm{D}^{1} \text { to Caud. Ped. } \quad . \quad & . & 8.75 & 9 \cdot 4 & 10 \cdot 0 & 10 \cdot 3 & 11 \cdot 3 & 11 \cdot 9 & 12 \cdot 3 & 13 \cdot 1 & 14 \cdot 2\end{array}$

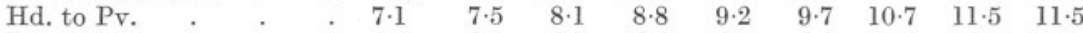

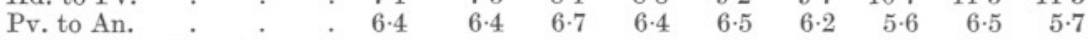

\begin{tabular}{lllllllllll} 
An. to Caud. Ped. $\quad . \quad$ & 4 & $4 \cdot 5$ & $5 \cdot 1$ & $5 \cdot 2$ & $5 \cdot 8$ & $6 \cdot 3$ & $7 \cdot 1$ & $7 \cdot 7$ & $7 \cdot 0$ & $8 \cdot 8$ \\
\hline
\end{tabular}

Total No. of Spec.

\begin{tabular}{lllllllll}
\hline 8 & 19 & 15 & 19 & 25 & 16 & 14 & 14 & 6
\end{tabular}

Referring as before to the values of (Hd. to $\left.\mathrm{D}^{1}\right)$ and (Pv. to An.), it is seen that the former interval increases as the value of $\left(\mathrm{L}_{\mathrm{B}}-\mathrm{Hd}\right.$.) increases, while the latter oscillates about a mean of $6 \cdot 3$, with perhaps a tendency even to decrease as $\left(\mathrm{L}_{\mathrm{B}}-\mathrm{Hd}\right.$.) increases. Thus the sprat agrees with the herring in that the distance from the pelvics to the anus does not increase during the transition from larva to adolescent, but differs from it in that the distance from the back of the brain to the first dorsal ray 
increases instead of remaining at a steady length. Comparing the sprat with the pilchard, it is seen that the interval $\left(\mathrm{Hd}\right.$. to $\left.\mathrm{D}^{1}\right)$ increases in the sprat but remains steady in the pilchard, whereas the interval (Pv. to An.) remains steady in the sprat but increases in the pilchard. These comparisons may be summarised thus :-

\section{HERRING. PILCHARD. SPRAT,}

$\mathrm{Hd}$. to $\mathrm{D}^{1}$. . Constant. Constant. Increases with $\mathrm{L}_{\mathrm{B}}$. Pv. to An. . . Constant. Increases with $\mathrm{L}_{\mathrm{B}}$. Constant.

Utilising the data in general, it has been found that the following equations may be used as mathematical summaries for the sprat:-

(1) $\left(\mathrm{Hd}\right.$. to $\left.\mathrm{D}^{1}\right) \quad=\cdot 412\left(\mathrm{~L}_{\mathrm{B}}-\mathrm{Hd}\right.$. $)+1 \cdot 79$.

(2) $\left(\mathrm{D}^{1}\right.$ to Caud. Ped.) $=\left(\mathrm{L}_{\mathrm{B}}-\mathrm{Hd}\right.$. $)-\left(\mathrm{Hd}\right.$. to $\left.\mathrm{D}^{1}\right)$.

(3) $\left(\mathrm{Hd}\right.$. to $\mathrm{Pv}$.) $=551\left(\mathrm{~L}_{\mathrm{B}}-\mathrm{Hd}\right.$. $)-3 \cdot 2$.

(4) $($ Pv. to An.) $\quad=6 \cdot 26$.

(5) (An. to Caud. Ped.) $=\left(\mathrm{L}_{\mathrm{B}}-\mathrm{Hd}\right.$. $)-(\mathrm{Hd}$. to Pv. $)-(\mathrm{Pv}$. to An.).

In Table 4, the values calculated from the above equations are shown for values of $\left(\mathrm{L}_{\mathrm{B}}-\mathrm{Hd}\right.$.), ranging from $18 \mathrm{~mm}$. to $26 \mathrm{~mm}$. As was the case with the pilchard, it is seen that the calculated values (given in Table 4) are not greatly different from the observed data (given in Table 3).

\section{TABLE 4.}

\section{Values of $\left(\mathrm{L}_{\mathrm{B}}-\mathrm{HD}\right.$.).}

Hd. to $\mathrm{D}^{1}$

$\mathrm{D}^{1}$ to Caud. Ped.

Hd. to Pv.

\begin{tabular}{|c|c|c|c|c|c|c|c|c|}
\hline 18 & 19 & 20 & 21 & 22 & 23 & 24 & 25 & 26 \\
\hline $9 \cdot 2$ & $9 \cdot 61$ & 10.02 & $10 \cdot 44$ & $10 \cdot 85$ & $11 \cdot 26$ & & 12.09 & \\
\hline $8 \cdot 8$ & $9 \cdot 39$ & $9 \cdot 98$ & 10.56 & $11 \cdot 15$ & $11 \cdot 74$ & & & \\
\hline $7 \cdot 09$ & $7 \cdot 66$ & $8 \cdot 23$ & 8.8 & $9 \cdot 37$ & $9 \cdot 94$ & $10 \cdot 52$ & 11.09 & $11 \cdot 66$ \\
\hline $6 \cdot 2$ & 6.26 & $6 \cdot 26$ & $6 \cdot 26$ & $6 \cdot 2$ & $6 \cdot 26$ & $6 \cdot 26$ & $6 \cdot 26$ & $6 \cdot 26$ \\
\hline $4 \cdot 65$ & 5.08 & $5 \cdot 51$ & $5 \cdot 94$ & $6 \cdot 37$ & $6 \cdot 80$ & $7 \cdot 22$ & $7 \cdot 65$ & \\
\hline
\end{tabular}

Pv. to An.

An. to Caud. Ped.

Thus for each unit of increase in the length of $\left(\mathrm{L}_{\mathrm{B}}-\mathrm{Hd}\right.$.) :

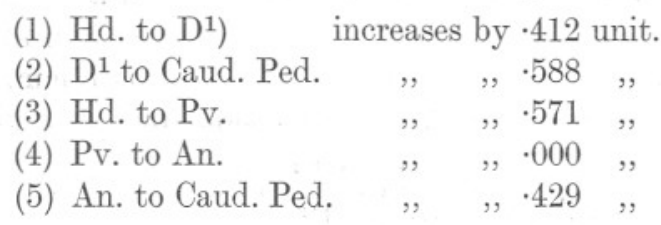

\section{Comparisons Between Species.}

Consider, first, the growth in length along the dorsal surface. An increase of one unit in the length of $\left(\mathrm{L}_{B}-\mathrm{Hd}\right.$.) is in each species the sum 
of the increases of (Hd. to $\left.\mathrm{D}^{1}\right)$ and ( $\mathrm{D}^{1}$ to Caud. Ped.). These latter are as follows :INCREASES PER UNIT INCREASE IN ( $\mathrm{L}_{\mathrm{B}}-\mathrm{Hd}$.).

\begin{tabular}{|c|c|c|c|c|}
\hline & & Herring. & Pilchard. & Sprat. \\
\hline $\mathrm{Hd}$. to $\mathrm{D}^{1}$. & . & . nil & nil & $\cdot 412$ \\
\hline $\mathrm{D}^{1}$ to Caud. Ped. & . & . $1 \cdot 0$ & $1 \cdot 0$ & $\cdot 588$ \\
\hline Total & . & . $1 \cdot 0$ & $1 \cdot 0$ & $1 \cdot 000$ \\
\hline
\end{tabular}

Thus for each unit increase in the length of $\left(\mathrm{L}_{\mathrm{B}}-\mathrm{Hd}\right.$.) the first dorsal ray is being brought relatively nearer the head in all three species, but more slowly in the sprat than in the herring or pilchard.

Unit increase in length of $\left(\mathrm{L}_{\mathrm{B}}-\mathrm{Hd}\right.$.) along the ventral surface is shared among three intervals, namely (Hd. to $\mathrm{Pv}$.), (Pv. to An.), and (An. to Caud. Ped.). In the three species these individual increments are :-

INCREASES PER UNIT INCREASE IN $\left(\mathrm{L}_{\mathrm{B}}-\mathrm{Hd}\right.$.).

\begin{tabular}{|c|c|c|c|c|}
\hline (Hd. to Pv.) & . & $\begin{array}{c}\text { Herring. } \\
.455\end{array}$ & $\begin{array}{c}\text { Pilchard. } \\
\cdot 4375\end{array}$ & $\begin{array}{r}\text { Sprat. } \\
.571\end{array}$ \\
\hline (Pv. to An.) . & . & nil & $\cdot 0625$ & nil \\
\hline (An. to Caud. Ped.) & & $\cdot 545$ & .5000 & $\cdot 429$ \\
\hline Total & . & . $1 \cdot 000$ & $1 \cdot 0000$ & $1 \cdot 000$ \\
\hline
\end{tabular}

It is seen that in the sprat the greater part of each unit increase in $\left(\mathrm{L}_{\mathrm{B}}-\mathrm{Hd}\right.$.) is added to the interval (Hd. to $\mathrm{Pv}$.), whereas in both the herring and pilchard, particularly the former, the major increase is in the interval (An. to Caud. Ped.). Dropping the use of symbols, this is to say that in the sprat the greater part of each unit increase in the bodylength is added in front of the pelvic fins, whereas in the herring and pilchard it is added post-anally.

It is instructive, also, to consider the changes in relative positions of the pelvic fins and anus as the result of unit increase in the length of $\left(\mathrm{L}_{\mathrm{B}}-\mathrm{Hd}\right.$.). Referring to Table 2, it is noted that in a pilchard in which $\left(\mathrm{L}_{\mathrm{B}}-\mathrm{Hd}\right.$.) is $18 \mathrm{~mm}$. the interval (Hd. to Pv.) measures $6.43 \mathrm{~mm}$. When $\left(\mathrm{L}_{\mathrm{B}}-\mathrm{Hd}\right.$.) is $19 \mathrm{~mm}$. the interval (Hd. to $\mathrm{Pv}$.) is $6.87 \mathrm{~mm}$. That is to say, an increase of $1 \mathrm{~mm}$. in $\left(\mathrm{L}_{\mathrm{B}}-\mathrm{Hd}\right.$.) results in an alteration of the proportion $\frac{\text { (Hd. to Pv. })}{\left(\mathrm{L}_{\mathrm{B}}-\mathrm{Hd} \text {. }\right)}$ from $\frac{6 \cdot 43}{18}$ to $\frac{6 \cdot 87}{19}$, or from $\cdot 357$ to $\cdot 361$. In effect this means that as the result of unit increase in $\left(\mathrm{L}_{\mathrm{B}}-\mathrm{Hd}\right.$.) the pelvics make a relative movement away from the head. Again referring to Table 2, it is noted that in a pilchard in which $\left(\mathrm{L}_{\mathrm{B}}-\mathrm{Hd}\right.$.) is $18 \mathrm{~mm}$. the interval (An. to Caud. Ped.) is $3.5 \mathrm{~mm}$., whereas at $19 \mathrm{~mm}$. the same interval measures $4.0 \mathrm{~mm}$. Thus an increase of $1 \mathrm{~mm}$. in $\left(\mathrm{L}_{\mathrm{B}}-\mathrm{Hd}\right.$.) results 
in an alteration of the proportion $\frac{\text { (An. to Caud. Ped.) }}{\left(\mathrm{L}_{\mathrm{B}}-\mathrm{Hd} \text {. }\right)}$ from $\frac{3 \cdot 5}{18}$ to $\frac{4 \cdot 0 \text {, }}{19}$ or from $\cdot 19$ to $\cdot 21$. This implies a relative movement of the anus towards the head. Hence in the pilchard each unit increase in $\left(\mathrm{L}_{\mathrm{B}}-\mathrm{Hd}\right.$.) causes a slight alteration in relative position of both pelvic fins and anus, the movement being away from the head in the case of the pelvics, but towards the head in the case of the anus.

Turning to the sprat, it is seen from Table 4 that when $\left(\mathrm{L}_{\mathrm{B}}-\mathrm{Hd}\right.$.) is $18 \mathrm{~mm}$. the interval (Hd. to Pv.) measures 7.09 mm., while at $19 \mathrm{~mm}$. it is $7.66 \mathrm{~mm}$. long. For unit increase in $\left(\mathrm{L}_{\mathrm{B}}-\mathrm{Hd}\right.$.) therefore the proportion $\frac{(\mathrm{Hd} \text {. to } \mathrm{Pv} \text {. })}{\left(\mathrm{L}_{\mathrm{B}}-\mathrm{Hd} \text {. }\right)}$ changes from $\frac{7 \cdot 09}{18}$ to $\frac{7 \cdot 66}{19}$ or from $\cdot 39$ to $\cdot 40$. Hence, as in the pilchard, the pelvics make a relative movement away from the head, but it is here very slight. Table 4 also shows that in the sprat in which $\left(\mathrm{L}_{\mathrm{B}}-\mathrm{Hd}\right.$.) is $18 \mathrm{~mm}$. the interval (An. to Caud. Ped.) measures $4.65 \mathrm{~mm}$., while at $19 \mathrm{~mm}$. it is $5.08 \mathrm{~mm}$. Unit increase in $\left(\mathrm{L}_{\mathrm{B}}-\mathrm{Hd}\right.$.) results in an alteration of the proportion $\frac{\text { (An. to Caud. Ped.) }}{\left(\mathrm{L}_{\mathrm{B}}-\mathrm{Hd} \text {. }\right)}$ from $\frac{4 \cdot 65}{18}$ to $\frac{5 \cdot 08 \text {, }}{19}$ or from $\cdot 26$ to $\cdot 27$. Hence, as in the pilchard, there is a relative movement of the anus towards the head for each unit increase in $\left(\mathrm{L}_{\mathrm{B}}-\mathrm{Hd}\right.$.). Now it has already been shown (Ford, 1) that in the herring the pelvics move backward and the anus forward relatively as $\left(\mathrm{L}_{\mathrm{B}}-\mathrm{Hd}\right.$.) increases, so that all three species are alike in this respect.

Before finishing this discussion of growth along the ventral surface, attention is directed to the relative lengths of the ventral body-intervals as $\left(\mathrm{L}_{\mathrm{B}}-\mathrm{Hd}\right.$.) increases. From Table 2 it is learned that in the pilchard of $18 \mathrm{~mm}$. the interval (Hd. to Pv.) is shorter than (Pv. to An.), but that with increasing length of $\left(\mathrm{L}_{\mathrm{B}}-\mathrm{Hd}\right.$.) the difference between these two intervals becomes less and less until at $23 \mathrm{~mm}$. the interval (Hd. to $\mathrm{Pv}$.) actually exceeds that of (Pv. to An.). From then onwards the margin of excess increases steadily. In the sprat, however (see Table 4), the interval (Hd. to Pv.) is already greater than ( $\mathrm{Pv}$. to $\mathrm{An}$.) when $\left(\mathrm{L}_{\mathrm{B}}-\mathrm{Hd}\right.$.) is at its smallest length of $18 \mathrm{~mm}$., and successive increases in $\left(\mathrm{L}_{\mathrm{B}}-\mathrm{Hd}\right.$.) merely augment the initial difference between the two intervals. Again, in both the pilchard and sprat the length of (Pv. to An.) at $18 \mathrm{~mm}$. is greater than that of (An. to Caud. Ped.), but as the fish grows in length the difference between the intervals diminishes until both are of the same length. This occurs at ca. $28 \mathrm{~mm}$. in the pilchard, but at ca. 21.5 $\mathrm{mm}$. in the sprat. At greater lengths of $\left(\mathrm{L}_{\mathrm{B}}-\mathrm{Hd}\right.$.) the interval (An. to Caud. Ped.) is longer than (Pv. to An.). 
Having considered growth in length along the dorsal surface, as distinct from that along the ventral surface, it is now desirable to discuss the one in conjunction with the other. We have seen that in the three species the dorsal fin makes a relative movement towards the head, the pelvics away from the head, and the anus towards it. How does the position of the first dorsal ray alter with respect to the pelvics and anus? Consider, first, the situation with regard to the first dorsal ray and the pelvics. The first dorsal ray is gradually shifting towards the head, but the pelvics away from it, and this holds in all three species. If carried on long enough, therefore, the time must come when the first dorsal ray, initially situated at a level well posterior to the pelvics, will come to lie immediately above the pelvics, and then later to be in front of them. This does actually occur in both the herring and pilchard, but in the sprat the process of relative shift appears to cease before the first dorsal ray has quite reached the level of the pelvics. A glance at the diagrams given by Lebour (2) will confirm this.

In the case of the first dorsal ray and the anus, we have seen that both tend to move relatively towards the head. Obviously, therefore, it is necessary to take into account the rate at which each is moving. On page 980 it was shown that for unit increase in $\left(\mathrm{L}_{\mathrm{B}}-\mathrm{Hd}\right.$.), the resultant increase in the interval ( $\mathrm{D}^{1}$ to Caud. Ped.) in the pilchard was 1.0 unit. This means that the first dorsal ray is brought $1 \mathrm{~mm}$. farther away from the end of the caudal peduncle. During this time the interval (An. to Caud. Ped.) increases by $.5 \mathrm{~mm}$., which means that the anus is brought farther forward by $.5 \mathrm{~mm}$. The anus and the first dorsal ray have thus become still further separated by $(1 \cdot 0-.5)=.5 \mathrm{~mm}$. In the case of the sprat, unit increase in $\left(\mathrm{L}_{\mathrm{B}}-\mathrm{Hd}\right.$.) brings about an increase of $.588 \mathrm{~mm}$. in the interval ( $\mathrm{D}^{1}$ to Caud. Ped.), and of $429 \mathrm{~mm}$. in the interval (An. to Caud. Ped.). The anus and the first dorsal ray in this species thus become further separated by $(.588-.429)=.159 \mathrm{~mm}$. as compared with $.5 \mathrm{~mm}$. in the pilchard. Similar working with the herring shows that the additional separation amounts to $\cdot 455 \mathrm{~mm}$.

\section{SUMMARY.}

Growth in length during the transition from larva to adolescent in the pilchard and sprat has been analysed, and simple straight-line equations deduced from observed data have been used to demonstrate how the different intervals along the dorsal and ventral surfaces of the body alter in length and proportion as development proceeds.

In the herring, pilchard, and sprat at least one of the body-intervals remains for all practical purposes unaltered in length during the transition. In the herring there are two such intervals, namely, (1) the 
distance from the back of the brain along the dorsal surface to the insertion of the first dorsal fin-ray, and (2) the distance from the insertion of the pelvic fins along the ventral surface to the anus. In the pilchard and sprat one of the above two remains stationary, but the other increases in length ; in the pilchard the fixed interval is the distance from the back of the brain to the first dorsal fin-ray, and in the sprat it is the distance from the pelvics to the anus.

In the herring and pilchard the greater part of each unit of increase in the length of the body ventrally from the back of the head to the end of the caudal peduncle is added in front of the pelvic fins, whereas in the sprat this is added post-anally.

Along the dorsal surface the first ray of the dorsal fin in the herring, pilchard, and sprat is gradually brought to lie relatively nearer and nearer to the head as development continues. Along the ventral surface the pelvics and anus also undergo alteration in relative position, the pelvics away from the head but the anus towards it.

In the herring and pilchard the relative forward movement of the first dorsal ray and the relative backward movement of the pelvics is carried on sufficiently to cause a "cross-over" in position on the body, so that whereas initially the first dorsal ray is posterior to the pelvic fins, it is eventually brought to lie anterior to the pelvics. In the sprat this does not occur, and the first dorsal ray remains posterior to the pelvics throughout development.

In the herring, pilchard and sprat a greater proportion of each unit increase in total length is added to the distance from the first dorsal ray to the end of the caudal peduncle than to the distance from the anus to the end of the caudal peduncle, so that as development proceeds the first dorsal ray becomes further and further removed from the anus.

During development the relative lengths of the different body-intervals alter appreciably. In the pilchard the distance from the back of the head to the pelvic fins is at first shorter than that from the pelvics to the anus, but ultimately it becomes the greater of the two. Similarly the distance from the anus to the end of the caudal peduncle commences by being smaller than that from the pelvics to the anus, but eventually comes to exceed it.

\section{LITERATURE CITED.}

1. Ford, E. Herring Investigations at Plymouth. VIII. The Transition from Larva to Adolescent. Journ. Mar. Biol. Assoc., N.S., Vol. XVI, No. 3, 1930.

2. Lebour, M. V. The Larval and Post-Larval Stages of the Pilchard, Sprat and Herring from Plymouth District. Journ. Mar. Biol. Assoc., N.S., Vol. XII, No. 3, 1921. 
